\title{
Unified information space as a basis for interaction of civil construction participants in value network
}

\author{
Tatyana Fedoseeva ${ }^{1, *}$ \\ ${ }^{1}$ Moscow State University of Civil Engineering (MGSU) National Research University, 26, \\ Yaroslavskoye sh., 129337, Moscow, Russia
}

\begin{abstract}
This paper presents the author's approach to the interaction of civil construction participants. The hypothesis about the need to change the nature and mechanism of relations between civil construction participants is put forward. The author offers an original approach to management and interaction systems in construction, which offers improving the interaction of construction participants on the basis of digital cooperation in the value network. Based on the methods of system analysis, the author defines the advantages of the parties from the association of construction participants and interaction in a single information space, lists the opportunities provided by joining a single information space, analyzes the features of the management process in the digital cooperation of civil construction participants in the value network, and presents the main activities in a single information space. A diagram of the relationship of construction participants in digital cooperation in the value network in a unified information space is presented. The expected effectiveness in implementing digital cooperation of construction participants in the value network is to increase the effectiveness of civil construction based on the principles of partnership of participants, transparency of interactions with the reduction of contradictions and restructuring of their goals to achieve the final result.
\end{abstract}

\section{Introduction}

The pace of increasing competition, technological breakthroughs in the fourth industrial revolution, and the use of innovations require changes in the traditional organization and management of construction and rapid implementation of these changes. Since management decisions to perform the previous functions, only at a more intensive pace, are no longer effective, changes are needed in the relationships of construction participants. One of the most important characteristics that an organization must have in an extremely dynamic environment is its readiness for changes, including changes in external conditions [1]. The constantly changing environment requires construction participants not only to be ready for changes, but also to react quickly to them [2]. Let me suggest that such a step in realizing the potential of the organizational component of a flexible company may be the cooperation of some participants of construction in the value network

${ }^{*}$ Corresponding author: FedoseevaTA@mgsu.ru 
With the rapid development of technologies, it is necessary to benefit from them by actively introducing them into the activities of companies, since technological innovations have a profound impact on enterprises and their activities [3-5]. Many of companies in different countries are implementing digitalization programs in their business practices [6].

Within the framework of the presented research, an attempt is made to solve a number of interrelated problems, such as:

- definition of digital cooperation,

- highlighting the opportunities offered by joining the value c network (VN),

- determining the advantages of construction participants from combining and interacting in a unified information space (UIS),

- defining the features of the management process when merging and working in the UIS,

- description of the relationship between construction participants in digital cooperation,

- consider the advantages and disadvantages of interaction between civil construction participants in the VN,

- listing of risk factors of construction participants in digital cooperation,

- assessment of the impact of value network on the interaction of construction participants.

In this paper, digital cooperation is understood as a form of interaction and labor organization, in which enterprises participate in the overall process of organizing and managing construction, creating partnerships between enterprises participating in the value network, through a single information space.

\section{Materials and methods}

According to research [7], productivity growth in construction is very small and changes more slowly than in other industries, since many industries are already in full speed with the introduction and application of "digitalization" [8]. Civil construction has come to the brink of "immersion" in "digital" opportunities, but it will not cross it. Only now digital technologies such as BIM modeling, document digitization and online information exchange, data collection using technology of Internet of things, and data mining (data mining) are beginning to be used in construction $[4,9,10]$. But even these technologies, which are already used in other industries and are constantly discussed in theory [11-12], are very difficult to find application in the practice of civil construction.

Well-developed organizational schemes and mechanisms for implementing these technologies are needed for a confident transition to them with the replacement of paper versions. The introduction of digital technologies will reduce routine tasks and increase the transparency of construction processes. The use of a mechanism for "digital" interaction of civil construction participants helps to identify and use potential reserves of the organization. Setting up such a mechanism will make available information that allows rational use of production reserves of various organizations participating in construction activities, increase the use of fixed assets in civil construction due to a denser load of their capacities, it is advisable to organize processes that affect the cost of construction products, affect the use of working capital. But it is not enough to simply transfer existing processes to a "digital" environment. A preliminary analysis of the processes of organization and management of civil construction is required, since disordered and inconsistent inter-organizational processes cause considerable losses.

The introduction of "digital" technologies is largely hindered by the imperfection of the existing management and interaction system (MIS) in civil construction. Rational organization and management of inter-organizational business processes in construction practice can be implemented through the cooperation of participants [13-16] of civil construction in the value network. It is necessary to change the nature of relations between 
civil construction participants to "network" and the mechanism of interaction to "digital", first of all, contributing to reducing the contradictions of construction participants and restructuring their goals to achieve the final result. "Digital" technologies should be a tool for building a qualitatively new system of management and interaction in construction. It is not necessary to adapt existing processes to technologies, it is necessary to design a management system in a new environment, building value network using mathematical methods of organization and planning, means of intellectual data collection and analysis that ensure the implementation of optimal solutions for the organization and management of civil construction. Nevertheless, despite the relevance of this problem, there is not enough discussion in the literature [3, 17] on organizational schemes and mechanisms for implementing digital technologies that ensure the dynamics of cooperation, changing and transforming the management and organization of construction activities.

A digital cooperation in the civil construction participants will allow reducing losses of working time and to streamline the organization of through supply companies, will provide the possibility of raising the rhythm of their work and interaction, contributes to the smoothing of the fragmentation of the construction, operational regulation of construction activities, the rationalization of standards of organization processes, the effective load capacity of participating organizations, and as a result, increase efficiency and productivity of construction. If we maintain the existing order and nature of management, the effectiveness of the introduction of "digital" technologies will be minimal, and may be negative. The existing system of organization, management and interaction of construction participants cannot be transferred to new technologies as it is.

Technologies are only one element of the management system, so "digitalization" shows the shortcomings of management and can help to eliminate them. That is why the transition to digital technologies should consist of two main areas: elimination of the shortcomings of the existing MIS in civil construction, which requires changing the nature of the relationships of construction participants and their integration in the value network (VN); actual work on the transition to digital technologies and UIS. Roles, responsibilities, and rules of interaction are defined when joining the $\mathrm{VN}$ in a single information space.

The goal of the value network is to meet the needs of the end user. Entry criteria can be quality of performance, process compatibility, and partner reliability. The value in the network in construction in this paper refers to a specific building product that with a certain degree of effectiveness should meet the needs of consumers, the needs of the customer/investor. Participants also derive value from the size of the network, the availability of information in it, and the coherence achieved through it. As a result of digital cooperation in construction, implemented on the basis of the principles of partnership and transparency, there is an increase in income due to the rational achievement of the results of construction activities and the desire of construction participants to work for a common goal.

\section{Results}

The main participants of the value network in civil construction can be: contractors (specialized construction and installation associations, construction departments), landlords or suppliers (material and technical resources, products, structures, equipment, machines and mechanisms), designers, architects. Self - regulating organizations, research organizations, marketing, financial, and state organizations can be considered as stakeholders that influence the success of the network; consumers include investors, developers, customers, developers, and users. An important participant of VN in the unified information space is the UIS coordinating organization, which takes on the role of coordinator of the value creation and interaction process. An example of the main scheme of interaction and cooperation of construction participants is shown in figure 1 . The coordinating organization can be a builder, 
developer, or general designer, as well as a coordinating council or a separate organization that performs only these functions. Preference should be given to the latter option, since, in this case, it is easier to maintain the independence of decisions made from the private interests of the individual company, subordination to the common goal and transparency of cooperation.

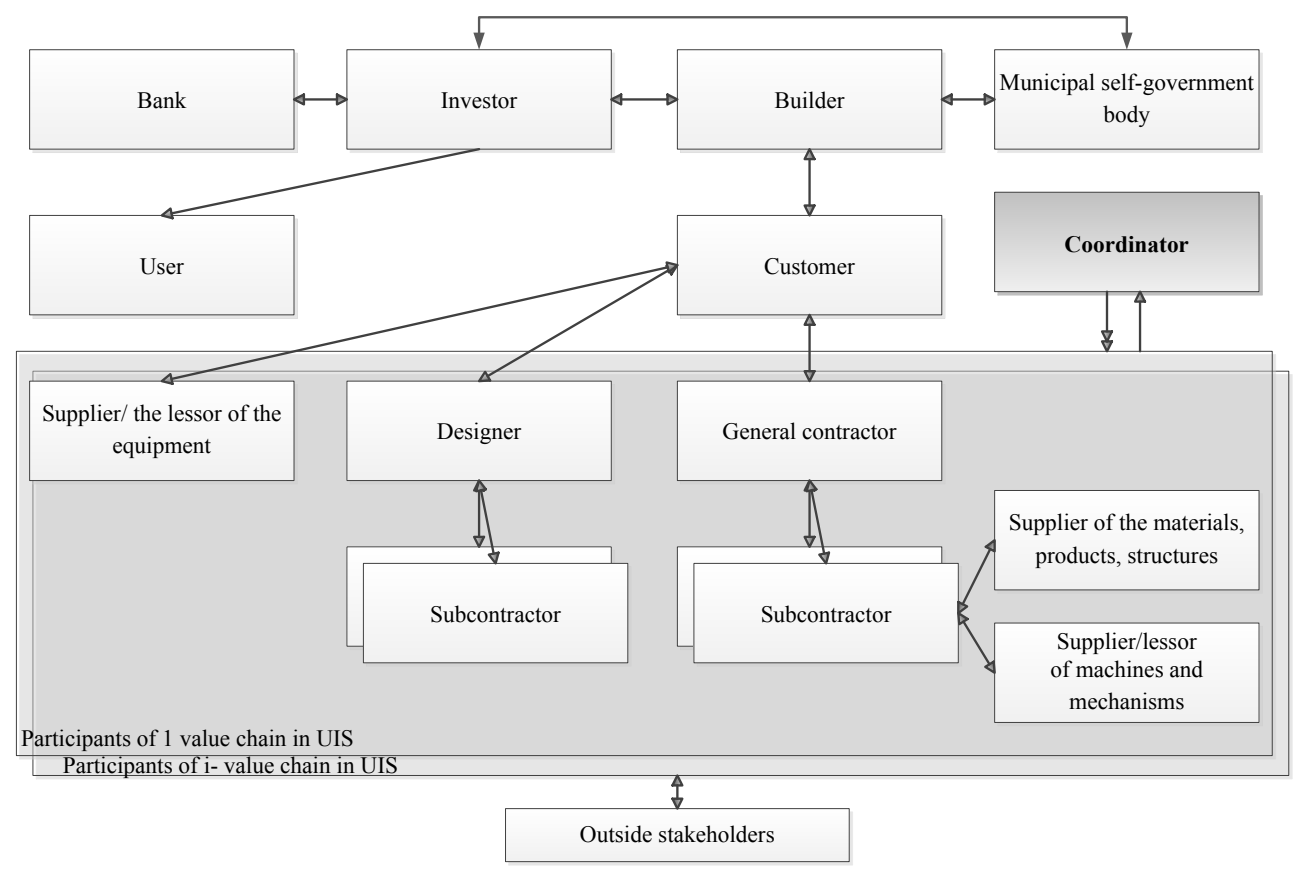

Fig. 1. Diagram of the relationship of construction participants in digital cooperation in the value network in a unified information space.

Summarizing the above, it should be noted that within the framework of digital cooperation, a unified information space organized through a web interface acts as a mechanism for interaction between civil construction participants, it is able to combine various information technologies (ERP, CALS, PLM, BIM, APS/SCM, MES) with the ability to organize compatibility with existing corporate solutions. For each UIS participant, information is stored that characterizes it (for example, rates, current workload, availability of different types of work or competencies, etc.). Participants are assigned specific roles or multiple roles. Each role is characterized by the implementation of a specific set of competencies. A specific competence may correspond to the ability to: perform a specific process (simple, complicated, complex, inter-object), conduct a specific type of activity (subjects of activities-investor, builder, customer, designer, contractor, etc.). Depending on the role in the UIS, the nature of actions in the UIS is determined. Possible actions in the UIS:

- creating a database of participants and delineating activities, processes, and competencies;

- entering characteristics and values for the project (splitting it into blocks), setting a goal;

- creating multiple alternative networks and selecting a specific one, including:

O selection of architects, designers, distribution of work by contractors, selection of suppliers and landlords by their competencies,

- selecting the most suitable construction participants based on their current workload,

○ distribution of work based on competencies, workload, opportunities integration of inter- 
organizational processes, etc.

- competence management (systematic integration of the different competences of the partners);

- managing the value network (including the construction process)

o coordination,

- regulation,

- control of execution,

- motivation,

- promotion of the network and management of its content, with the regulation of the rights of network members and conditions for entering it.

When creating several alternative value network (figure 2), it is proposed to calculate many solution options based on the participants' base and their competencies, among which to select the best option for the value network. One of the criteria for selecting a VN option is the degree of performance of the construction organization.

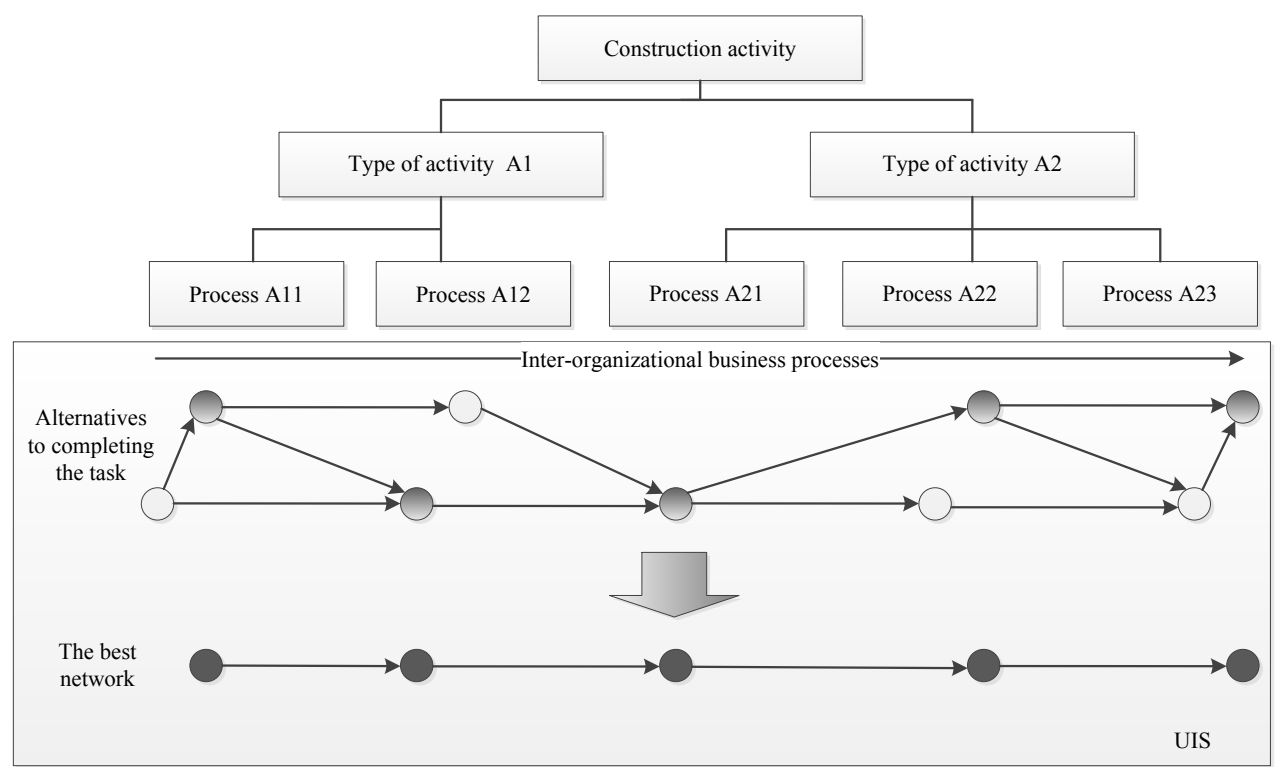

Fig. 2. The value network in construction in the UIS.

The effectiveness of the functioning and interaction of construction organizations should be measured by performance characteristics and limit parameters of deviation from each of them, taking into account the relationship of deviations. It is necessary to coordinate the work on deviations, combine data on various types of deviations, analyze and periodically adjust business processes. Characteristics that allow to evaluate the performance of a construction organization: duration, cost, labor productivity, resource consumption, quality, feasibility of project goals, flexibility.

The value network analysis is primarily a visual representation of exchange models and relationships between participants, reflecting relationships, business transactions, and information exchange.

After choosing a specific alternative to the network, the tasks of creating and streamlining relationships between the subjects of investment and production processes, as well as the tasks of exchanging information between participants in civil construction should be solved. It is safe to say that information is the main component of the value that participants exchange when they join the VN. Previously, information was seen as a cost, but now information exchanges can be seen as a source of value creation. The cost is derived from the system's 
ability to receive and analyze information. The increase in the volume of information, the importance of its timely receipt and correct interpretation, combined with the improvement of information technologies that allow for appropriate actions with information, leads to the emergence of new business models and causes a synergistic effect from the combination of utilities (implementation of the described nature of network relationships using digital technologies).

Opportunities provided by creating a CV:

- dynamic cooperation of participants of civil construction

- shortening the response time to events,

- continuous multi-party information exchange of network members (including data from Internet of things),

- coordination of mutual exchange of resources and services,

- clear coordination of actions (activities) of all organizations involved in construction and administratively previously separated,

- reducing paper document flow,

- flexibility in organizing and coordinating construction and management processes

- integration of different stages of production,

- expanding the range of available know-how,

- extension of the competences of employees,

- access to partner organizations' resources.

Advantages for construction from combining the CV in the UIS:

- optimization of expenses on the allocation of resources and equipment,

- optimization of business processes,

- improving the efficiency of information, goods and services exchange processes,

- cost minimization,

- increase efficiency in the value network,

- timely response to events,

- distribution of risks among participants of the value network.

Combining civil construction participants in a value network based on a unified information space allows for regulatory impacts on the management process (MP), taking into account its features. Influence on the features of the management process in the case of digital cooperation, allows:

- increase the dynamism of MP,

- maintain the continuity of the MP at the expense of the UIS functionality when tracking the results of construction and implementation of control actions,

- ensure that the MP is cyclical, that is, search for the most effective ways to achieve the goal and / or adjust it, if it deviates from it

- implement a strict sequence of stages and main groups of MP operations,

- reduce the discreteness of management by using convenient tools for deep analytical work, realizing the potential of practical actions of managers in relation to the managed system,

- maintain the stability of MP.

\section{Discussion}

In the existing schemes of interaction of participants in construction activities, almost no such type of relationship as cooperation is used, mainly the absorption and consolidation of several legal entities into one. That is, the organizational structures of the participants change, there is a rigid dependence and, very often, there is no way back, or it is even more complicated 
than the changes made. And in the case of digital cooperation, the process of entering and exiting a value network is relatively easy for its participants, while each participant of the network remains with their business. In addition to consumer value, cooperative networks create value for each participant. For organizations with different amounts of equity and the number of employees employed in it, the positive factors of cooperation may differ (table 1).

Table 1. Positive factors of association in the VN for construction organizations of various categories.

\begin{tabular}{|l|l|}
\hline $\begin{array}{c}\text { Category of construction } \\
\text { organizations }\end{array}$ & \multicolumn{1}{c|}{ Positive factor } \\
\hline $\begin{array}{l}\text { Small and medium } \\
\text { businesses }\end{array}$ & $\begin{array}{l}\text { Increasing competitiveness in relation to large concerns and } \\
\text { holdings }\end{array}$ \\
\hline Concerns and holdings & $\begin{array}{l}\text { Using a new technology for organizing internal business processes } \\
\text { and inter-company interaction }\end{array}$ \\
\hline All organization & $\begin{array}{l}\text { Modernization of relations between participants in the investment } \\
\text { and construction process with reduction of participants' } \\
\text { contradictions and restructuring of their goals to achieve the final } \\
\text { result }\end{array}$ \\
\hline
\end{tabular}

Another positive factor is the entry of large competitive companies into the value network, since their positive impact will extend to the rest of the network participantssuppliers, consumers, and even competitors. As a result, participants in the value network contribute to each other's competitiveness. Success based on the positive influence of a competitive company will lead to further growth of the company's competitiveness. The competitive advantage of $\mathrm{VN}$ participants is created by a combination of their activities that can not always be repeated. However, small businesses are often more innovative than large organizations, since the creation of small businesses is often associated with an attempt to bring a new technology or innovation to market. The presence of small businesses in the value network can increase its value due to their flexibility and the technologies used.

Participation in the value network should be on an equal terms, with the possibility of leaving it. It is important to note that the maximum effect can be obtained only with a longterm partnership, since organizations that do not have previous experience of interaction and cooperation, and do not trust each other, may spend efforts that do not match the results of short-term cooperation when trying to work together.

There are also risks involved. The established exchange of confidential data, including information about know-how, is accompanied by the risk of using data not only for its intended purpose. It is necessary to be aware of the risks and strive to organize safe work with data and information. So, to reduce the possibility of risks, you should provide access to data for a specific purpose. Another category of risks in digital cooperation is the risk of unilateral use of cooperation. This scenario is minimized if the coordinator of the UIS of the value network is a specialized organization that is not engaged in any other type of activity in construction and has no other interests than the most effective implementation of its activities that generate its income.

The disadvantages of implementing the UIS include the cost of information technology. A possible solution to this disadvantage appears if the company that coordinates the activities of the unified information space and bears the costs of its development will be a financial beneficiary of the operation of the UIS (for example, to charge a fee for access to it), or in case of financing from the budget. For example, when creating a regional construction cluster. Also, do not forget about the return on investment due to the positive impact of digital cooperation, described above.

\section{Conclusions}


General analysis of the situation shows that there are favorable conditions for construction organizations to move along the path of digital cooperation, and many of them have all the necessary capabilities for this. Digital technologies are being used in an increasing number of industries, and the only way to benefit from them and continue to thrive is to be flexible and not be afraid of change. Once again, we would like to emphasize that the change in the nature and mechanism of relations between civil construction participants will ensure the modernization of relations between civil construction participants. Digital cooperation of construction participants will allow organizing more dynamic cooperation by implementing constant information exchange of network members, coordinating mutual exchange of resources or services, reducing paper document flow and response time to events. It is designed to simplify the creation of partnerships, as well as to implement the processes of organization and management of construction through the use of modern information technologies. The proposed approach to the interaction of civil construction participants in value network through a single information space is promising and has a basis for its practical implementation. This allows us to conclude that the problem of detailed study of the impact of the specifics of construction organizations (type of activity, organizational structure, legal form) or the scheme of organization of construction with participation in the process of digital cooperation can be considered as a promising direction for further research.

\section{References}

1. G. Schuh, R. Anderl, J. Gausemeier, M. ten Hompel, W. Wahlster, Industrie 4.0, Maturity Index. Managing the Digital Transformation of Companies (acatech STUDY) (Herbert Utz Verlag, Munich, 2017)

2. R. Woodhead, P. Stephenson and D. Morrey, Automation in Construction 93, 35-46 (2018) doi: https://doi.org/10.1016/j.autcon.2018.05.004

3. G. Elia, A. Margherita, G. Passiante, Technological Forecasting and Social Change 150, 119791 (2020) doi: https://doi.org/10.1016/j.techfore.2019.119791

4. A. Churbanov, Yu. Shamara, Vestnik MGSU, Proceedings of the Moscow State University of Civil Engineering 13.7(118), 824-835 (2018) DOI: 10.22227/19970935.2018.7.824-835

5. The Future for Construction Product Manufacturing : Digitalisation, Industry 4.0 and the Circular Economy (Construction Products Association, London, 2016) URL: www.constructionproducts.org.uk

6. F. Fossen, A. Sorgner, Journal of Business Research (2019) https://doi.org/10.1016/j.jbusres.2019.09.019

7. F. Barbosa, J. Woetzel, J. Mischke, M. J. Ribeirinho, M. Sridhar, M. Parsons, N. Bertram, S. Brown, Reinventing construction through a productivity revolution (McKinsey Global Institute, 2017) https://www.mckinsey.com/industries/capitalprojects-and-infrastructure/our-insights/reinventing-construction-through-aproductivity-revolution

8. New Forms of Work in the Digital Economy, OECD Digital Economy Papers (OECD Publishing, Paris, 2016) doi: https://doi.org/10.1787/5jlwnklt820x-en

9. C. Merschbrocka, B.E. Munkvold, Computers in Industry 73, 1-7 (2015) Doi: https://doi.org/10.1016/j.compind.2015.07.003

10. A. Sawhney, A.R. Khanzode, S. Tiwari, Report for Royal Institution of Chartered Surveyors (RICS, London, 2017) rics.org/insights

11. E. Gusakova, Vestnik MGSU, Proceedings of the Moscow State University of Civil 
Engineering 13.1(112), 14-22 (2018) doi: 10.22227/1997-0935.2018.1.14-22

12. S. Kumar, P. Tiwari, M. Zymbler, J Big Data 6, 111 (2019) doi:10.1186/s40537-0190268-2

13. S. Haghbin, P. Davoudi, Procedia Technology 16, 979-987 (2014) doi: https://doi.org/10.1016/j.protcy.2014.10.051

14. E. Shevtshenko, I. Poljantchikov, K. Mahmooda, T. Kangilasski, A. Norta, Procedia Engineering 100, 159-68 (2015). doi: https://doi.org/10.1016/j.proeng.2015.01.354

15. H. Xue, Sh. Zhang, Y. Su, Z. Wu, R. J. Yang, Journal of Cleaner Production 184, 490502 (2018) doi: https://doi.org/10.1016/j.jclepro.2018.02.258

16. A. Montarnal, W. Mu, F. Benaben, J. Lamothe, M. Lauras, N. Salatge, Information Sciences 453, 30-49 (2018) doi: https://doi.org/10.1016/j.ins.2018.03.041

17. W.D. Du, S.L. Pan, N. Zhou, T. Ouyang, Information Systems Journal 28.6, 1158-1175 (2018) doi: https://doi.org/10.1111/isj.12176 